\title{
Terrestrial fugitive plastic packaging: the blind spot in resolving plastic pollution
}

Christopher Wallis PhD, MRSC, MRSB

Vice President of Innovations, Polymateria Ltd, London, UK

(cw@polymateria.com)

\begin{abstract}
An opinion piece highlighting the role plastic packaging, particularly single-use commodity packaging, contributes to global plastic pollution. The article specially unpacks the quantities found on land in comparison to those found in the marine environment. While land-based plastic pollution is approximately three times bigger in terms of scale, the article notes that current research and development and policy strategies are solely focused upon marine-based pollution. The article seeks to address this by proposing strategies to readdress the balance in attention and to engage academia, government and the public in a polyvalent effort towards resolving the ecological damage being caused to our environment.
\end{abstract}

Plastic usage and the subsequent awareness of the waste that it generates have been attracting growing attention through both the mainstream media and the scientific community since 2012. The breakthrough in public attention, however, came with Blue Planet II in 2017. ${ }^{1}$ The consistently excellent combination of the British Broadcasting Corporation's Natural History Unit and Sir David Attenborough highlighted, in the final episode of this extraordinary series, the ecological effect and damage of humankind's 'plastic addiction' on the natural environment, particularly on oceans. The emotional scenes of marine animals entangled by fishing nets or suffocating in plastic bags released a tirade of public anger and a backlash against the use of 'unnecessary' plastic packaging. The increased awareness has emphasised not only the scale of the problem, but also the unseen ecological threat of fugitive plastics on the health of the planet's ecosystems.

The quantity of fugitive plastic pollution released into the environment per year is estimated to be $32 \%$ of the total production of plastic for the corresponding year. ${ }^{2}$ More interesting is that $44 \%$ of all plastic produced belongs to the packaging sector, a proportion that far outweighs any other sector's use of plastics (shares (\%) of market sectors: packaging, 44.8; building and construction, 18.8; consumer and institutional products, 11.9; transportation, 6.7; electrical/electronic, $3 \cdot 8$; industrial machinery, $0 \cdot 8$; others, $13 \cdot 2$; see the supporting information of the article by Geyer et al. ${ }^{3}$ ). In 2015, for example, 146 million metric tonnes of plastic packaging was produced, with an estimated $96.6 \%$ used and disposed of within the same year. ${ }^{3}$ This equates to 141 million metric tonnes of primary plastic packaging waste generated in the year 2015. If the global leakage/generation of fugitive plastics is assumed to be $30 \%$ of the packaging waste produced, this would suggest that 42 million metric tonnes of fugitive plastic packaging was produced in 2015. This quantity of fugitive plastic packaging for 2015 alone clearly indicates that commodity plastic packaging is the most identifiable proportion of plastic waste and, due to its commodity use, the most highly likely to be disposed of in both responsible and irresponsible ways. The 'blind spot' in the public awareness of plastic pollution is that, when commodity plastic packaging is littered or escapes collection, it is three times more likely to be so on land rather than in the oceans.

To focus on plastic packaging on land against that in the oceans, a study from 2015 highlighted how these fugitive plastics end up in oceans after escaping collection. ${ }^{4}$ It was found that, on average for the total amount of plastic pollution generated, $75 \%$ remained 'on land' in a terrestrial environment while $25 \%$ migrated (over the course of that year) into the oceans. (See the paper by Jambeck et al., ${ }^{4}$ based on 192 coastal countries producing 100 million metric tonnes of coastal plastic waste, of which 32 million metric tonnes is mismanaged (or littered) on land and 8 million metric tonnes is leaked into the oceans. See also the webpage of the Jambeck Research Group. ${ }^{5}$ ) If these proportions are applied to the most prevalent types of plastic resins used for packaging, it creates an interesting insight into identifying the types of plastics where more attention needs to be focused (Figure 1). It also suggests that the problem starts predominately on land, before moving into the oceans. Recent studies identifying the ten most prevalent rivers carrying fugitive plastic waste into the oceans seem to support this hypothesis. ${ }^{6}$ In fact, it has been suggested that the only way to resolve plastic pollution in the oceans is to 'cut off' the supply of the fugitive plastic from the land into the oceans. ${ }^{4}$

Polyolefin-based plastics of polyethylene (PE) (low-density PE (LDPE)/linear LDPE and high-density PE) and polypropylene (PP) contribute the highest combined share with $31 \%$, followed by $\mathrm{PE}$ terephthalate (PET) at $10 \%$, while polystyrene (PS), poly(vinyl chloride) (PVC) and polyurethane (PUR) had a combined share of only $3 \cdot 4 \%$. These numbers correlate well with the plastic packaging market, with PE and PP being ubiquitous for single-use packaging films, as well as for caps, closures and containers. When a gas barrier is necessary, either to keep food from spoiling (e.g. meat containers, fruit punnets or processed microwavable food containers) or for carbonated drinks (e.g. sparkling water or soda), PET is virtually the sole packaging plastic of choice, and this is therefore reflected in its relatively individually high share of the market. PUR 


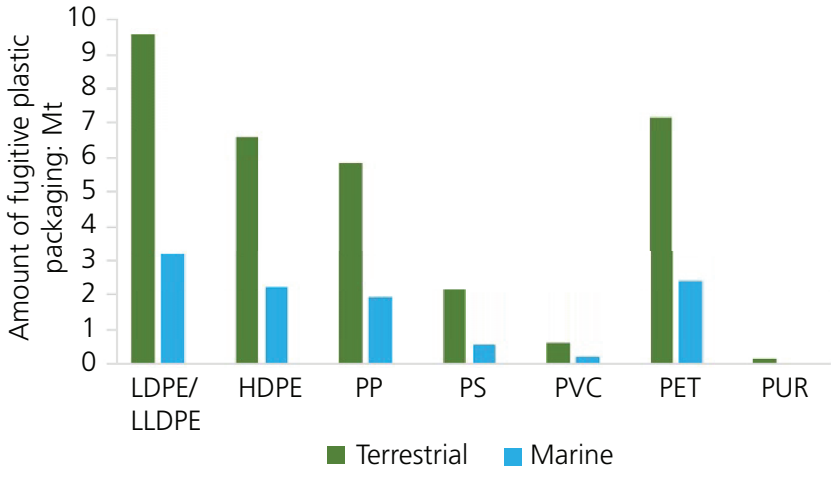

Figure 1. Approximate quantities of fugitive plastic packaging generated in terrestrial and marine environments, based on production and leakage rates for 2015. HDPE, high-density polyethylene; LDPE, low-density polyethylene; LLDPE, linear low-density polyethylene; PET, polyethylene terephthalate; PP, polypropylene; PS, polystyrene; PUR, polyurethane; PVC, poly(vinyl chloride)

and PVC are more often used in durable plastic applications, and PS is being banned or phased out in many countries globally.

Even more concerning from an environmental point of view is the extrapolation of these numbers from 2015 to 2050 (Figure 2). Based on a continued growth rate of the global plastic packaging market of $1.9 \%$ per year, it is to be expected that over 60 million metric tonnes of plastic waste would be littered in the terrestrial environment in 2050 , with the marine quantity also doubling to approximately 20 million metric tonnes. (These predicted estimations have been calculated based on an annual growth in the plastic packaging sector of $1.9 \%$ (based on market growth trends over the last 3 years) with a constant rate of fugitive plastic production of $30 \%$. The terrestrial- and marine-based figures were calculated from the total $30 \%$ of fugitive plastic at 75 and $25 \%$, respectively.) Cumulatively, however, this rate of fugitive plastic packaging generation would mean that 1.6 billion metric tonnes would accumulate in terrestrial environments from 2015 to 2050, an amount that is breathtaking in its size and could cause catastrophic damage to land ecosystems globally.

The blind spot in the fight against the reduction of fugitive plastic pollution therefore comes from an overly weighted focus on marine plastic pollution, with not enough emphasis (policy and strategies) on terrestrial fugitive plastic. Many are already stating that, once the plastic is in the oceans, the only remedy is removal and recovery, but a long-term future solution would be to stop this from happening in the first place. Despite this, funding is being targeted only towards marine plastic pollution, ${ }^{7}$ with very few strategies or calls for evidence being proposed to identify the sources and quantity of terrestrial plastic pollution. ('Europe's leading chemical industry association has set aside about $€ 650000$ (US\$680 000) for two studies: one to determine microplastics hazards and one to develop a model of how microplastics are

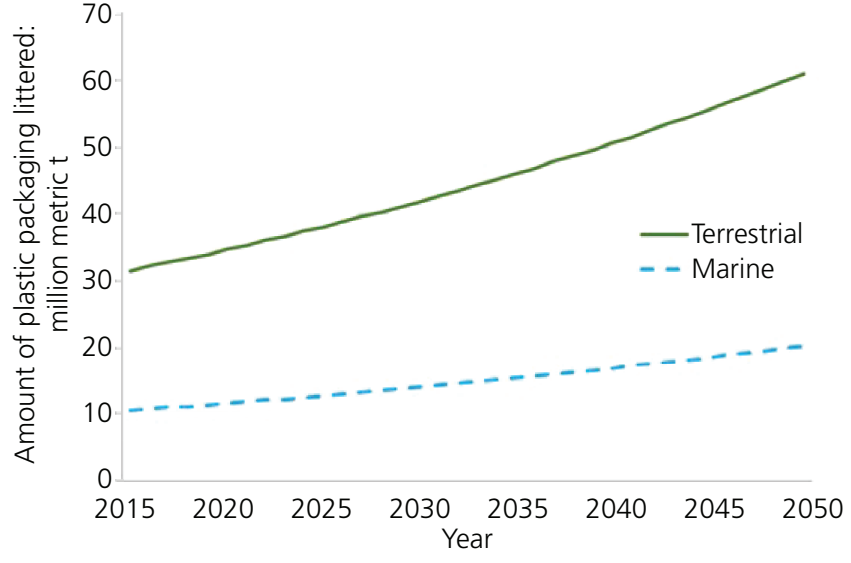

Figure 2. The predicted quantity of fugitive plastic packaging leaked into the terrestrial and marine environments, based on 1.9\% growth per year in the production of global plastic packaging

transported in the aquatic environment and where they end up'.7) This misunderstanding has been further compounded just recently by the release of the EU directive ${ }^{8}$ on single-use plastic packaging. The directive calls for member states to implement penalty schemes and bans on certain single-use plastic products, such as straws, containers and bags. Furthermore, the directive solely highlights the marine-based fugitive plastic problem while erroneously contending that terrestrial-based biodegradable and compostable plastic solutions would be restricted under the directive, as it claims that these types of plastics are incompatible with recycling. This is a misplaced judgement based on an erroneous understanding of the global (and accumulating) crisis, not to mention going against the prevailingly academic thinking, which is that, to solve the problem of marine-based plastic pollution, one must 'shut off' the source of land-based fugitive plastics leaking into the waterways and eventually the oceans. There is evidence that with the incentive to innovate and apply disruptive thinking to a stagnated value chain that technological advances can be introduced into plastic packaging that can make them more sustainable, recyclable and biodegradable. (The rise of bio-based plastics and compostable plastics is such an example.) Moreover, the EU's assertion that a 'silver-bullet' solution will resolve the problem to the satisfaction of both society and the plastic industry is completely misplaced. The plastic packaging industry is complex and nuanced due to the nature of the materials that need to be packaged. While some packaging may be, quite rightly, unnecessary, other types of packaging are critical to ensuring delivery of quality products, including the correct preservation of the item to avoid spoiling. (The classic example here is that a cucumber wrapped in plastic film will last three times longer than an unwrapped one. Hence, the importance and necessity of single-use plastic packaging is to help conserve food.)

In short, the EU directive, along with similar policies in the USA which call for bans on certain plastic packaging products and 
highlight only marine plastic pollution, is a missed opportunity to recognise the scale of the problem for what it truly is and where the result of the problem is accumulating: on land, in terrestrial environments all over the globe and on a scale several times bigger than that in the oceans.

Government and policymakers should be using the public awareness and desire for action as a unique chance to reinvent an industry through different forms of innovation throughout the entire value chain. Innovations spanning the design stage to consumer use, as well as reinvigoration of end-of-life scenarios to expand the use, inventiveness and scale of recycling and biodegradation (composting and on soil), would create new jobs, new technologies and new business opportunities. In addition, this is an ideal moment to harness public support and interest through schemes that are already growing around beach cleaning and removal of plastic litter already in the environment. All of this, combined with targeted solutions to specific plastic packaging (single-use or other), is the most viable and polyvalent solution to seeing the circular economy's goals coming to fruition within the framework of a new plastic economy. Most importantly, it would remedy the potential future environmental disaster on the horizon by reducing the leakage of plastics into the environment, particularly on land, by providing incentives to reuse and recycle more while having innovations within plastics to stop their bioaccumulation within the natural habitats of the planet.

Moving forward, there needs to be a general recognition of the terrestrial plastic problem and how this relates to plastic packaging and consumer behaviour. The three key elements that need addressing are the following.

- Increased awareness of the scale of terrestrial plastic pollution. Incentives from the government and industry to fund research into quantifying land-based plastic pollution and its sources and plastic types are a key foundation stone.

- Classification of single-use plastic packaging into types of plastics and commodity use in order for the industry, brands, supermarkets and consumer groups to evaluate and identify where innovation is needed for biodegradable and recyclable improvements and also where reduction is possible.

- A strategic global policy drive to create and promote innovation throughout the entire supply chain of plastics and their end-of-life fates. Funding should be targeted towards applicative, scalable solutions to existing plastic resin grades, not just niche alternatives. Region-based funding should also use this opportunity to highlight calls for research and development into specific environmental problems related to their geographical locations.

These three key steps should be the start of a heightened global awareness of the problem and ecological damage caused by terrestrial fugitive plastics. Plastic product bans should be used sparingly and only where the application is frivolous. Innovations in polymeric materials need to be the driver of change and should be encouraged at all levels of the government and industry and, importantly, communicated to the general public so that they are aware that action is being taken. Plastics and plastic packaging became the go-to material of choice for all commodity goods because of the resources spent at the time in making them strong, light and cheap. To prevent these innovations from being lost, but so that their consequences do not do irreparable damage to the planet, there is now a need to reinvest to the same level, to rethink the after-life versatilities of plastics to ensure a sustainable continuation of the 'plastic fantastic' story.

\section{REFERENCES}

1. BBC NHU (British Broadcasting Corporation Natural History Unit) (2017) Blue Planet II. BBC NHU, London, UK.

2. Ellen MacArthur Foundation (2016) The New Plastics Economy: Rethinking the Future of Plastics. Ellen MacArthur Foundation, Cowes, UK.

3. Geyer R, Jambeck JR and Law KL (2017) Production, use and fate of all plastics ever made. Science Advances 3(7): article e1700782.

4. Jambeck JR, Geyer R, Wilcox C et al. (2015) Plastic waste inputs from land into oceans. Science 347(6223): 768-771.

5. Jambeck Research Group (2019) https://jambeck.engr.uga.edu/ landplasticinput (accessed 18/06/2019).

6. Schmidt C, Krauth T and Wagner S (2017) Export of plastic debris by rivers into the seas. Environmental Science and Technology 51(21): 12246-12253.

7. Scott A (2019) All-consuming plastics. C\&EN 97(5): 28-33.

8. EU (European Union) (2019) Directive 2019/904 of the European Parliament and of the Council of 5 June 2019 on the reduction of the impact of certain plastic products on the environment. Official Journal of the European Union L155/1. 